\title{
Evaluating the GPCC Full Data Daily Analysis Version 2018 through ETCCDI indices and comparison with station observations over mainland of China
}

\author{
$\mathrm{Yu} \mathrm{Yu}^{1}$ (D) $\cdot$ Udo Schneider $^{2} \cdot$ Su Yang ${ }^{1} \cdot$ Andreas Becker $^{2} \cdot$ Zhihua Ren $^{1}$ \\ Received: 9 September 2019 / Accepted: 7 August 2020 / Published online: 14 August 2020 \\ (C) The Author(s) 2020
}

\begin{abstract}
The new $1^{\circ} \times 1^{\circ}$ resolution global Full Data Daily Analysis Version 2018 published by the Global Precipitation Climatology Centre (GPCC) of Deutscher Wetterdienst was compared with an analysis of the measurements from the national dataset over the mainland of China with regard to four of the 27 ETCCDI indices (http://etccdi.pacificclimate.org/list_27_indices.shtml) commonly used to determine extreme precipitation (Rx5day, R10mm, CDD and SDII). After extreme value check, integrity check, and homogeneity check, the observations from 2327 surface stations covering the years from 1982 to 2016 fulfilled the criteria for the evaluation. The in situ daily precipitation data were interpolated onto a $1^{\circ} \times 1^{\circ}$ grid over the mainland of China by employing Shepard's angular and distance weighting algorithm. The four aforementioned indices were then calculated on the national station-based analysis being referred to as STA. Moreover, the aforementioned gridded GPCC Full Data Daily product was directly utilized to calculate the same indices (FDDA). The China national means of Rx5day, R10mm, CDD and SDII calculated from FDDA and STA had similar variations and trends with high correlation coefficients, and the mean biases between FDDA and STA were $2.5 \mathrm{~mm}, 1.2$ days, 0.0 day and $0.3 \mathrm{~mm}$ respectively. The trends of Rx 5 day, R10mm and SDII are increasing, whereas the trend of CDD is negative. The distributions of the grid mean and the grid trends of indices over China from FDDA and STA show similar patterns too, indicating that the FDDA shows a surprisingly high fidelity in reproducing almost the same patterns in the four ETCCDI indices chosen compared with the STA-based analysis.
\end{abstract}

\section{Introduction}

Precipitation is an essential climate variable to assess the fresh water supply of a region or nation. Therefore, its long-term changes are of high relevance for the public and the government in charge. In order to improve the understanding of the global water cycle, the Global Precipitation Climatology Centre (GPCC) inaugurated at Deutscher Wetterdienst in 1989 on request of the World Meteorological Organization (WMO) has successively developed a series of global grid products backward to 1891 with optional spatial resolutions. These precipitation analysis datasets are based on all available

Andreas Becker

andreas.becker@dwd.de

1 National Meteorological Information Centre, China Meteorological Administration, Beijing 100081, China

2 Global Precipitation Climatology Centre (GPCC), Deutscher Wetterdienst, 63067 Offenbach am Main, Germany daily and monthly in situ gauge measurements, processed by GPCC's own semiautomatic data quality control system (Schneider et al. 2014). The products are useful for a number of applications ranging from near real-time flood and drought monitoring to long-term climate analyses (Becker et al. 2013; Schneider et al. 2017). The GPCC Full Data Monthly Product at $0.5^{\circ} \times 0.5^{\circ}, 1^{\circ} \times 1^{\circ}$ or $2.5^{\circ} \times 2.5^{\circ}$ resolution underwent several comparisons with other gridded datasets which were based on gauge-only interpolation or gauge and satellite combinations focusing on the bias and correlation of annual or seasonal precipitation (Negrón Juárez et al. 2009; Kidd et al. 2012; Gu and Adler 2015; Prakash et al. 2015).

Precipitation varies from year to year and over decades and changes in quantity, frequency and intensity with a direct influence of global warming (Trenberth 2011). Focusing on the changes of temperature and precipitation extreme events, the Expert Team on Climate Change Detection and Indices (ETCCDI) defined a set of 27 widely used indices calculated from surface station observations. This allows for the analysis of the distribution and changes of climate extremes in global 
scale (Frich et al. 2002; Kiktev et al. 2003; Alexander et al. 2006).

In a recent study, Zittis (2018) analysed the changes of some of the drought and extreme rainfall indices over Middle East and North Africa based on three gridded global daily precipitation datasets including the GPCC Full Data Daily Analysis V1.0. Lacking a more precise reference, it is hard to tell which one among the three was more like a benchmark. In 2018, the most recent GPCC Full Data Daily Analysis was published at $1^{\circ} \times 1^{\circ}$ resolution. Compared with its predecessor (Version 2015), its temporal coverage was extended to cover the period from 1982 to 2016, and it included an overall enlarged station database. Due to data policy, the daily precipitation observations from high-density surface stations over China are usually not freely available to the entire scientific community. Thus, there were roughly 700 stations obtained across China to construct the GPCC Version 2018 grid daily precipitation data. This study shall basically demonstrate the suitability of the GPCC FDDA dataset from a climatic perspective and show the performance of the new GPCC daily analysis in describing precipitation extremes on a regional scale by comparison with an analysis of highdensity surface meteorological station measurements based on the entire collective available to China only. In doing so, four indices were selected from the 27 ETCCDI ones and utilized to evaluate the new GPCC daily product over the mainland of China, being strongly influenced by the East Asian monsoon and a precipitation that shows great variability especially in summer (Zhai et al. 1999; Zhang and Zhou 2011). The four indices and their typical usages are as follows: (1) maximum 5-day precipitation index (Rx5day) to describe changes in potential flood risks, (2) heavy precipitation days index $(\mathrm{R} 10 \mathrm{~mm})$ to diagnose the wet part of the precipitation distribution, (3) consecutive dry-day index (CDD) to describe the lower tail of the precipitation distribution often referred to as a drought indicator, and (4) the simple daily intensity index (SDII) to provide useful information about the relationship between changes in extreme conditions and other aspects of the distribution of daily precipitation (Kiktev et al. 2003). The indices R50mm and R95pTOT are also commonly utilized to diagnose the extremely heavy precipitation. As shown in Zhai et al. (2005), only at the southeast coast of China and lower reaches of the Yangtze River, the 95th percentiles of daily precipitation during 1961-90 partly exceed $40 \mathrm{~mm}$, so it maybe not proper to choose R50mm in this study considering the entire mainland of China. Also not all of the stations collected in our research covered the reference period from 1961 to 1990; hence, the index Rx5day was preferred to be used here.

The procedures of surface station data and GPCC product processing and gridding are presented in Section 2. Section 3 discusses the methods for calculating national mean values, trends and their significance. The comparison of the four indices Rx5day, R10mm, CDD and SDII in annual national mean, grid mean and grid trends are shown in Section 4. In more detail, the patterns of the four selected indices are illustrated which provide an insight into the characteristics of extreme precipitation across China including its trend behaviour. The sensitivity of the calculated indices against the size of the underlying data from two different data sources is also demonstrated. Finally, Section 5 provides the conclusions.

\section{Data}

\subsection{Surface station data processing}

The daily precipitation data measured from the national surface stations over mainland of China from 1982 to 2016 covers the entire time range of GPCC daily analysis used in our study. Stations from adjacent countries have been added to the analysis to compensate the inadequate surface station density along the borders of China, and these precipitation data were taken from the Global Historical Climatology Network Daily (Menne et al. 2012) or the Global Surface Summary of the Day datasets, both published by National Centres for Environment Information of NOAA. ${ }^{1}$ All station data has been quality controlled and checked for integrity and homogeneity as described in the following.

\subsubsection{Extreme value check}

As two of our four chosen ETCCDI indices are sensitive against extreme precipitation, the corresponding values were checked first of all. In this step, the highest $1 \%$ of the precipitation data from each station or precipitation higher than $50 \mathrm{~mm}$ per day $\left(P_{e}\right)$ is evaluated by comparison with its neighbour sites. As the extreme values may not peak in the same day with the neighbouring stations if an event happens over night, they are checked by accumulating with its previous and following days' precipitation amount. The searching range for neighbour stations is enlarged from $0.5^{\circ}$ to $1.0^{\circ}$ then to $2.0^{\circ}$, until at least one station could be found.

The evaluated 3-day accumulated precipitation was divided into three intervals as 50 150, 150 250 and $>250 \mathrm{~mm}$. Table 1 shows the thresholds applied for the screening, and they were set to be about $10 \%$ of the checked value. In the condition of station sparsity, which means there were only one or two stations in the searching range, the thresholds were relatively lower. If there was no accumulated value from neighbour stations exceeding the threshold, the $P_{e}$ was regarded as an error value, and therefore, it was neglected.

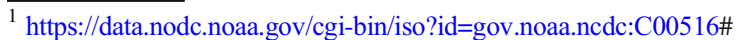


Table 1 Thresholds for extreme precipitation checking

\begin{tabular}{lll}
\hline Checked value & \multicolumn{2}{l}{ Neighbour station } \\
\cline { 2 - 3 } & Number of stations & Threshold value \\
\hline$>250 \mathrm{~mm}$ & $1-2$ & $10 \mathrm{~mm}$ \\
{$[150,250] \mathrm{mm}$} & $1-2$ & $25 \mathrm{~mm}$ \\
& $\geq 3$ & $5 \mathrm{~mm}$ \\
{$[50,150] \mathrm{mm}$} & $1-2$ & $15 \mathrm{~mm}$ \\
& $\geq 3$ & - \\
\hline
\end{tabular}

\subsubsection{Integrity check}

Only the stations, which match with the data completeness requirements of ETCCDI and the criteria from Herold et al. (2016), were used in our study. At any station, no more than three daily values may be missing in any single month; otherwise, the entire month was considered missing. Similarly, no more than 15 days in any year may be missing; otherwise, the entire year was considered missing. For each station located in the mainland of China, at least $70 \%$ of the 1982-2016 periods and at least three of the first and last 5 years should fulfil the annual integrity requirement. For the stations beyond the border of China, at least $60 \%$ of the years were required to pass the integrity check.

\subsubsection{Homogeneity check}

Station relocation, changes in measuring techniques and changes in observational routines may add inhomogeneity to station data records. Four renown homogeneity test methods, standard normal homogeneity test (SNHT, Alexandersson 1986), Buishand range test (Buishand 1982), Pettitt test (Pettitt 1979) and von Neumann ratio test (von Neumann 1941), were applied to check the annual wet days (daily precipitation $>=1 \mathrm{~mm}$ ) for each station. According to Wijngaard et al. (2003), the threshold for wet day definition, the mathematical formulation of the four tests, and the critical values for their test statistics were used in our study.

Each series with break points detected at $1 \%$ significance level by more than three out of four tests was screened out from the following study.

\subsubsection{Gridding of daily data}

Two thousand three hundred twenty-seven surface stations, located as red dots in Fig. 1a, passed the integrity check and homogeneity check described before. Also, it is shown that the station density in East China is much higher than the west. In order to create a nearly 'true' reference, these stations were fully used in this study. There are two ways to obtain gridded indices. One is to grid the station daily precipitation first and then to compute the indices for the grids; the other is to calculate the indices at each station and then grid the indices. The difference in the order of calculation has an impact on the gridded indices and their interpretation. In the first case, the grid box value is an index that describes an aspect of the behaviour of the daily grid box mean values of the precipitation (Zhang et al. 2011). Also the 1st way is consistent with calculating the precipitation extreme indices from the gridded GPCC daily precipitation analyses. As the precipitation extreme indices have apparent spatial discontinuity, the precipitation values from stations were interpolated to grid cells first, and then the four precipitation extreme indices were calculated. In doing so, the Shepard's angular and distance weighting (ADW) algorithm (Shepard 1968; New et al. 2000) was applied to interpolate the in situ daily precipitation data into gridded data with $1^{\circ} \times 1^{\circ}$ resolution. The searching range for every cell from its centre was initially set to $110 \mathrm{~km}$ and subsequently doubled or tripled until at least one neighbouring station had been enclosed. If there were more than eight stations in the first searching radius, the stations were ranked by their distances from the grid centre to subsequently use the eight closest located stations.

\subsubsection{Indices calculation}

Based on the gridded daily precipitation data, the gridded indices Rx5day, R10mm, CDD and SDII with resolution of $1^{\circ} \times 1^{\circ}$ over mainland of China were calculated which were referred as STA indices in the following.

\subsection{Index diagnosis from GPCC analysis}

The GPCC Full Data Daily Analysis Version 2018 covering the years from 1982 to 2016 at $1^{\circ} \times 1^{\circ}$ resolution was directly used to calculate the indices Rx5day, R10mm, CDD and SDII grid-by-grid (FDDA). Figure $1 \mathrm{~b}$ demonstrates the number of surface stations contained in the grid of the GPCC daily analysis over mainland of China, and the total number of station is around 700. In East China, it shows a good coverage, but in Northwest China especially in the west part of Tibetan Plateau, the station density was sparse as there are actually very few stations over that region shown in Fig. 1a.

\section{Comparison method}

The method proposed by Jones and Hulme (1996) was used for the spatial interpolation on a latitude-longitude grid. In doing so, the latitude cosine value of the centre point of the grid was used as weight for each grid value to obtain the average for all grid cells covering the whole mainland of China. Then a linear model $(y=a+b x)$ was used to obtain the trend of the considered variables by minimizing the chi- 
Fig. 1 (a) Spatial distribution of the 2327 surface stations (red dots) deployed in this study for STA and number of stations per $1^{\circ}$ grid. (b) Number of surface stations per $1^{\circ}$ grid contained in the GPCC Full Data Daily Analysis Version 2018 (FDDA) over mainland of China
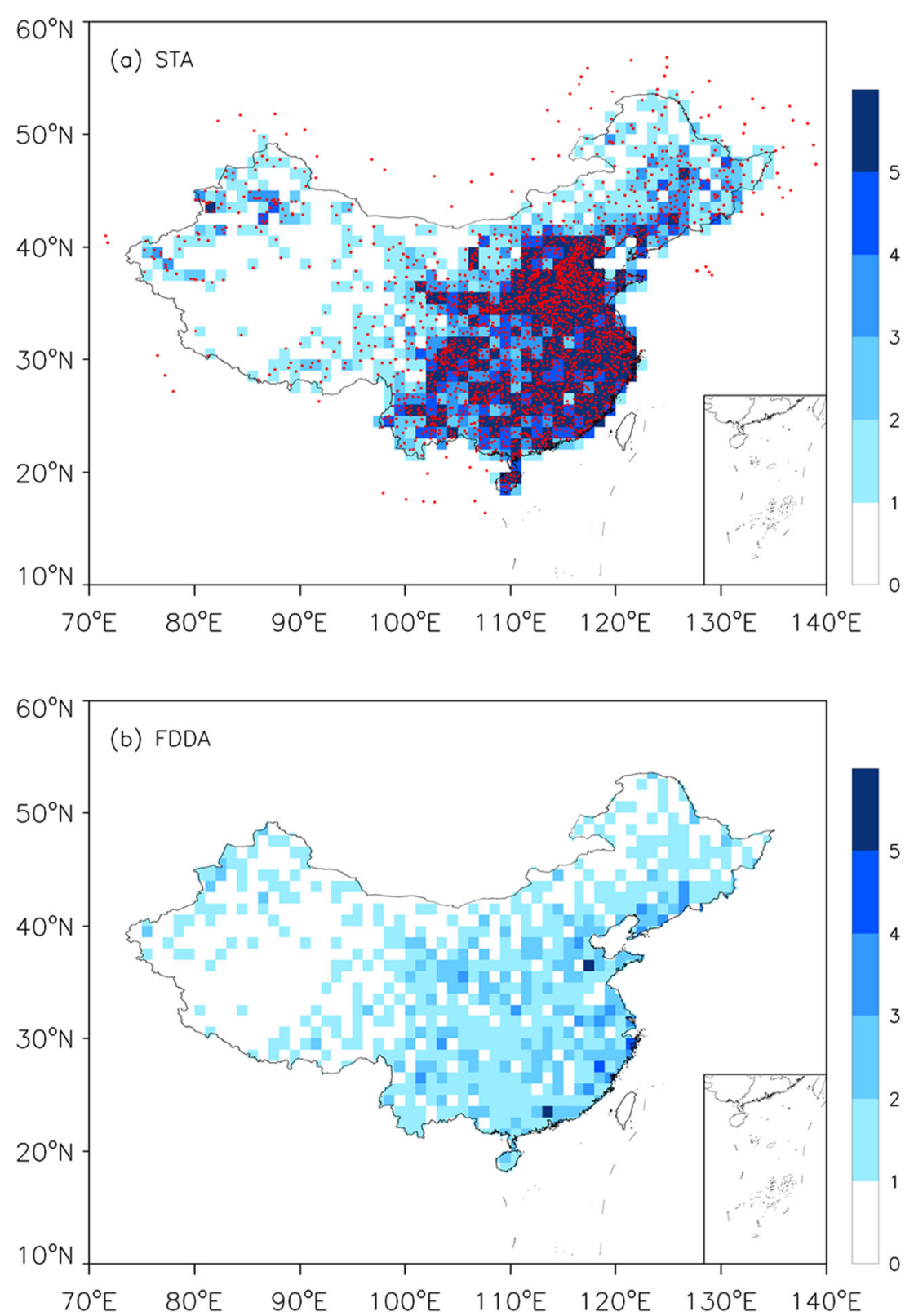

square error statistic. For the significance test, the nonparametric Mann-Kendall approach was used. Moreover, two other metrics, namely, the mean bias (MB, the average of FDDA minus STA) and correlation coefficient (CC, calculated from FDDA and STA annual series), were also diagnosed for the index-based comparison.

\section{Results}

\subsection{National mean comparison of the indices diagnosed}

The changes of Rx5day, R10mm, CDD and SDII national mean values over time are shown in Fig. $2 \mathrm{a} \sim \mathrm{d}$, respectively.
The cumulative percentage distribution of the four indices based on the grid data are also presented in panel Fig. $2 \mathrm{e} \sim \mathrm{h}$. All series of four indices based on STA or FDDA had similar variations, and the correlation coefficients were no less than 0.94 (see Table 2).

The STA-based Rx5day ranges from 70.9 to $87.3 \mathrm{~mm}$ in the 35 years, while the FDDA-based Rx5day varies in the 73.8 to $90.4 \mathrm{~mm}$ interval. The differences between national mean FDDA and STA are all positive in every analysed year, and the mean discrepancy is $2.5 \mathrm{~mm}$. In Fig. 2e the FDDA and STA do not show apparent difference until the cumulative percentage reaches $55 \%$, and from the 60 percentage upwards, FDDA becomes larger than STA. Similar as the first index, R10mm also has a positive bias of the FDDA-based values versus the STA ones during the whole analysed period. The 

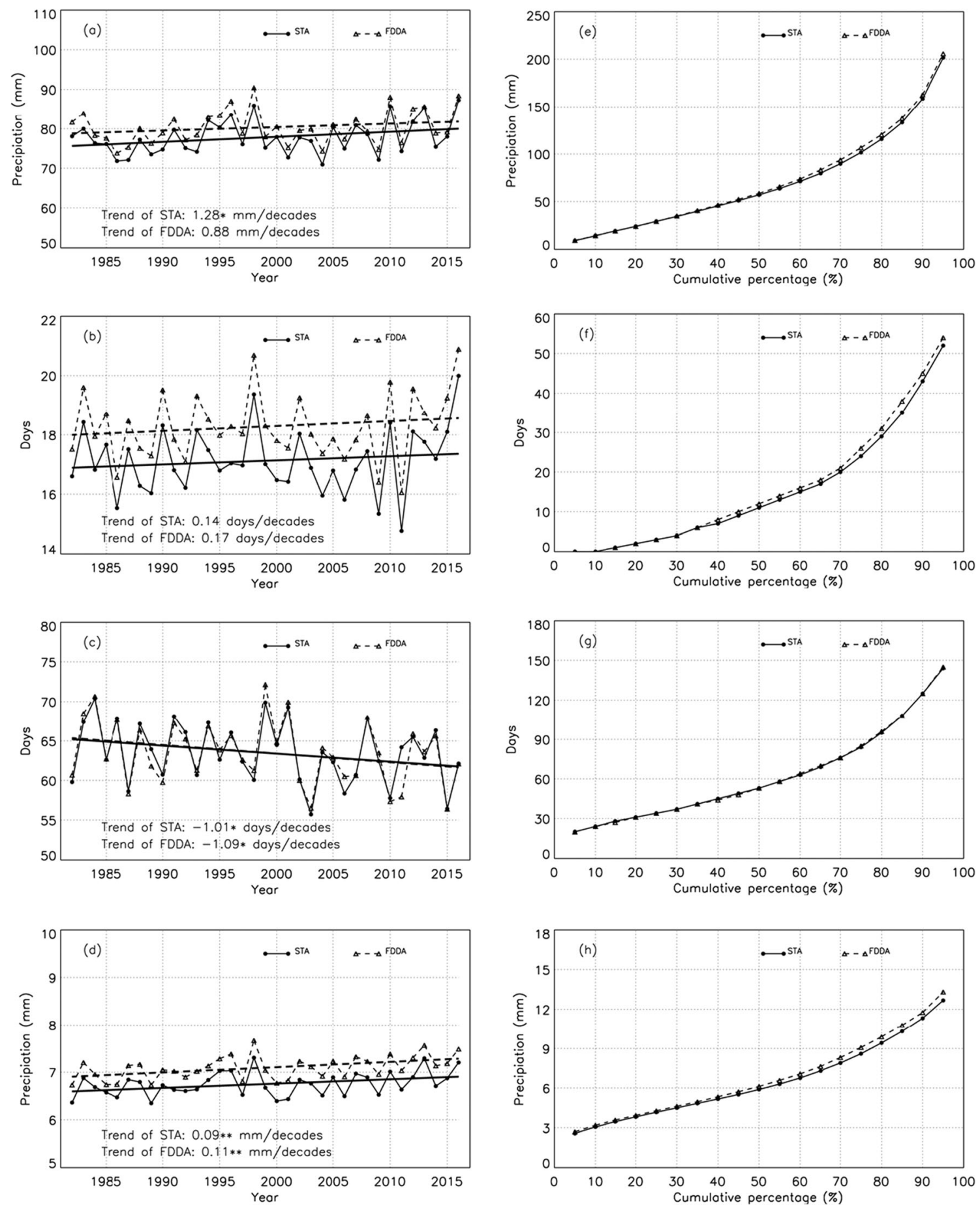

Fig. 2 National mean of (a) Rx5day, (b) R10mm, (c) CDD and (d) SDII annual variations (significant trends for $p \leq 0.1$ are indicated by *, while for $\mathrm{p} \leq$ 0.05 are indicated by $* *) ;(\mathbf{e}) \sim(\mathbf{f})$ cumulative percentage of Rx5day, R10mm, CDD and SDII from STA and FDDA based on the grid data

mean difference is 1.2 days and the largest one 1.5 days occurring at the year 2012, while the CC is 0.99 which is the highest among all four indices. As shown from the cumulative percentage statistics in Fig. 2f, FDDA is the same with STA in the lower part of the cumulative percentage, but from the 40 percentage upwards, FDDA becomes larger than STA. In Fig. 2c the national mean CDD from FDDA is very close to the STA-based one with the mean bias around 0 days, and the largest bias is -6.3 days occurring in 2011, while the other discrepancies are within \pm 2.3 days. Further analysis of the FDDA shows that there were 18 and 5 days of daily data missing in January and December of 2011, respectively. 
Table 2 Differences between the national mean of FDDA and STA across the mainland of China

\begin{tabular}{llllll}
\hline Index & CC & Mean bias & Minimum bias & Maximum bias & RMSE \\
\hline Rx5day & 0.97 & $2.5 \mathrm{~mm}$ & $0.2 \mathrm{~mm}$ & $4.5 \mathrm{~mm}$ & $2.73 \mathrm{~mm}$ \\
R10mm & 0.99 & $1.2 \mathrm{~d}$ & $0.9 \mathrm{~d}$ & $1.5 \mathrm{~d}$ & $1.16 \mathrm{~d}$ \\
CDD & 0.94 & $0.0 \mathrm{~d}$ & $-6.3 \mathrm{~d}$ & $2.3 \mathrm{~d}$ & $1.38 \mathrm{~d}$ \\
SDII & 0.97 & $0.3 \mathrm{~mm}$ & $0.2 \mathrm{~mm}$ & $0.4 \mathrm{~mm}$ & $0.35 \mathrm{~mm}$ \\
\hline
\end{tabular}

Since there is usually little precipitation during winter especially across Northwest China, this mainly explains the CDD discrepancy in year 2011. The comparison of FDDA and STA for the CDD cumulative percentage statistics (Fig. 2g) yields perfect consistence. The STA-based SDII changes from 6.3 to $7.3 \mathrm{~mm}$ during 1982-2016 in Fig. 2d, while the FDDA-based SDII values are all greater than the STA-based ones during the same year. Their differences are ranging from 0.2 to $0.4 \mathrm{~mm}$, and the mean bias is $0.3 \mathrm{~mm}$.

For the entire period, both the STA- and FDDA-based SDII show significant increasing trends, which were 0.09 and $0.11 \mathrm{~mm}$ per decades, respectively. As for Rx5day and R10mm, they all have positive trends, but only the trend of STA-based Rx5day is significant which is $1.28 \mathrm{~mm}$ per decade. Unlike the other three indices, CDD decreases significantly with -1.01 days and -1.09 days per decade for STA and FDDA, respectively. These results correspond well with those of a most recent study of Peng et al. (2018) that focused on extreme precipitation in China too but analysed a longer period from 1960 to 2017 with a small data collection of 743 sites. Their national means of R10mm and SDII show the same increasing trends, and their variabilities were similar to our results.

\subsection{Spatial distribution comparison}

\subsubsection{Rx5day index}

From the mean STA-based Rx5day distribution (Fig. 3a), it can be seen that the southeast area (south of $35^{\circ} \mathrm{N}$ and east of $109^{\circ} \mathrm{E}$ ) features values higher than $150 \mathrm{~mm}$. For FDDA (Fig. $3 b$ ), values of the same level are also concentrated in the same region, but the area coverage is relatively smaller, as holds for the positions of the dividing lines such as $100 \mathrm{~mm}, 50 \mathrm{~mm}$ and $25 \mathrm{~mm}$ indicating that the high precipitation events in the southeastern region are slightly underestimated by GPCC FDDA in comparison to the STA analysis. As shown in Fig. $3 \mathrm{c}$, the MB of FDDA-based Rx5day values to the STA-based ones are within $\pm 25 \mathrm{~mm}$ in almost entire China except the southern fringe area of the Tibetan Plateau. It is assumed that this is caused by sampling errors in the precipitation interpolation across this area of substantial station scarcity.

\subsubsection{R10mm index}

Figure 4 shows the distributions of the R10mm index mean values across China, and both the STA- and FDDA-based analyses show similar spatial patterns with the highest values located in Southeast China. Similar as Rx5day, almost all the MB fell in the range from -5 to +5 days except the southern edge of Tibetan Plateau. The FDDA- and STA-based analyses show a high level of correlation in the east of China.

\subsubsection{CDD index}

As for the mean annual CDD distribution (Fig. 5), the Taklamakan Desert located in the south part of Xinjiang province is the area with more than 120 consecutive dry days, while the middle east of China hosts the minimum value of CDD which is under 30 days. In the Southeast of China, the MB between FDDA- and STA-based analyses is almost always within the interval of -5 to 5 days. On the contrary, in parts of Xinjiang province, the MB can be greater than 20 days, and in the southern edge of Tibetan Plateau, the MB can be lower than -10 days. However, in most of the western areas of China, the MBs are mainly positive but show a substantial spatial variability in this area of data scarcity.

\subsubsection{SDII index}

In Fig. 6, it can be seen that the area in East China where the STA-based SDII index exceeds $12 \mathrm{~mm}$ is located along or near the coastline, while the location of FDDA SDII index for the same quantity shows a slight offset from STA's. Also, the MB ranges mainly from -1 to $1 \mathrm{~mm}$ in almost entire China, while in the southern fringe area of the Tibetan Plateau, the MBs are greater than $3 \mathrm{~mm}$. In the east of China, the FDDA- and STA-based analyses are again highly correlated.

\subsection{Trends comparison}

Figure 7 shows the spatial distribution of Rx5day, R10mm, CDD and SDII annual trends, and the corresponding patterns are similar between FDDA and STA. As for CDD, except for Southwest China, almost the whole nation shows declining trends. Especially in the northern part of Northwest China, western part of Northeast China and central part of Tibetan Plateau, the declines are significant. In Northeast China, the three indices Rx5day, R10mm and SDII also show negative trends, indicating that extreme precipitation events become less frequent and severe in that region and even the mean rain becomes weaker, whereas in Southeast China especially along the coastline, the quantity and frequency of extreme precipitation were both increasing and so does the mean precipitation amount. 

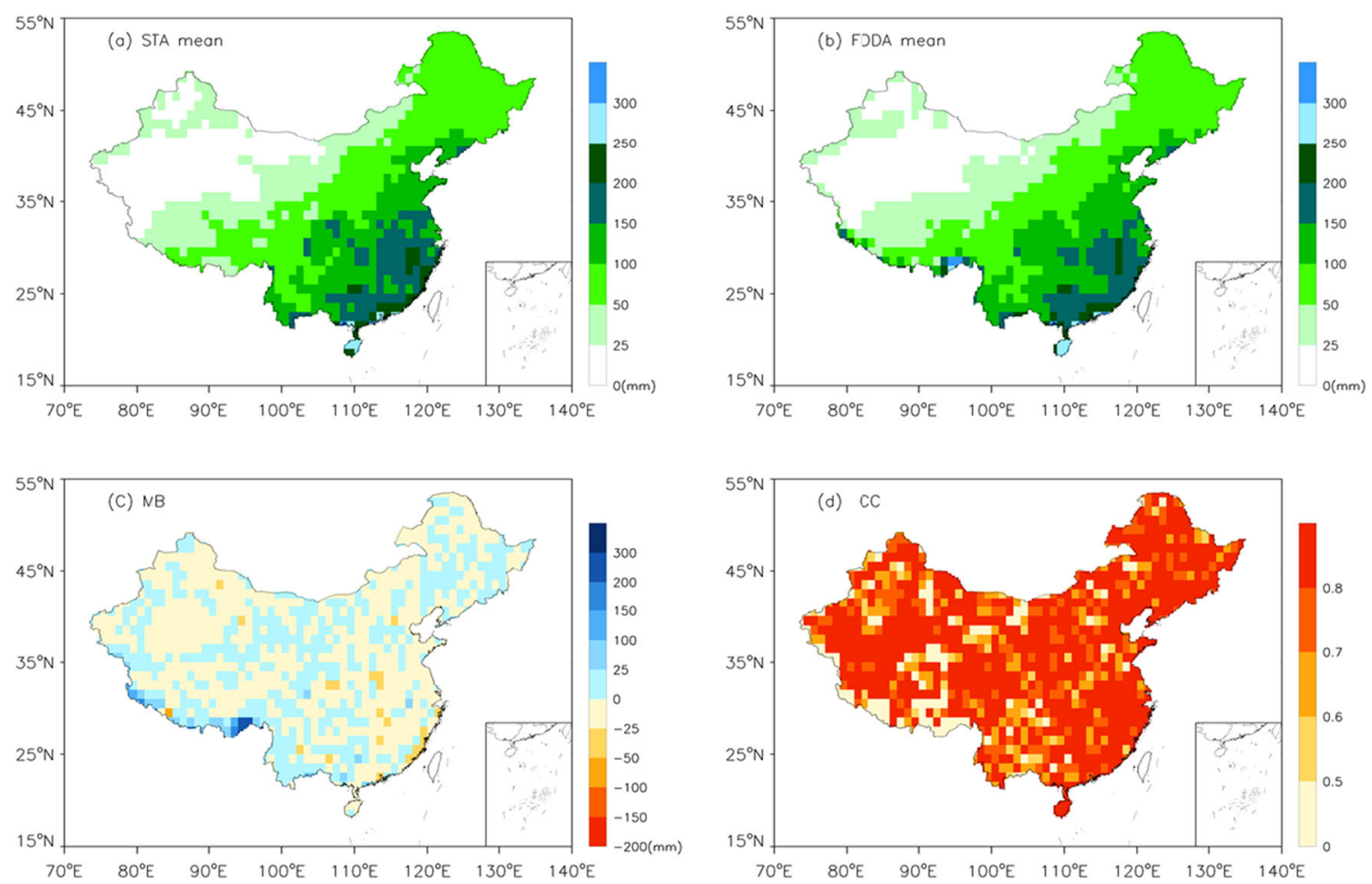

Fig. 3 Distribution of Rx5day index: (a) STA mean; (b) FDDA mean; (c) mean bias between FDDA and STA; (d) correlation coefficient of FDDA and STA
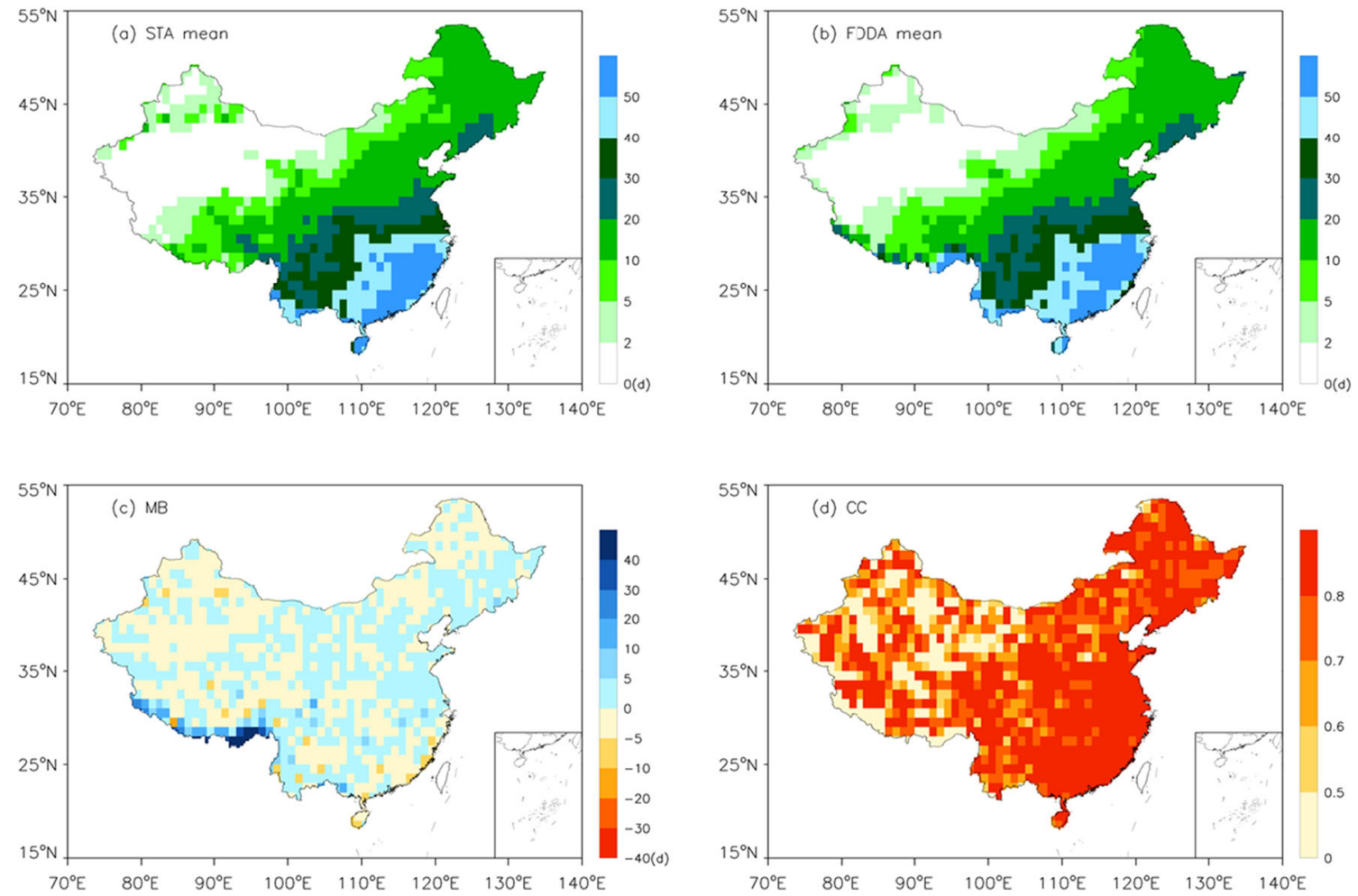

Fig. 4 Distribution of R10mm index: (a) (d) the same as Fig. 3 but for R10mm index 

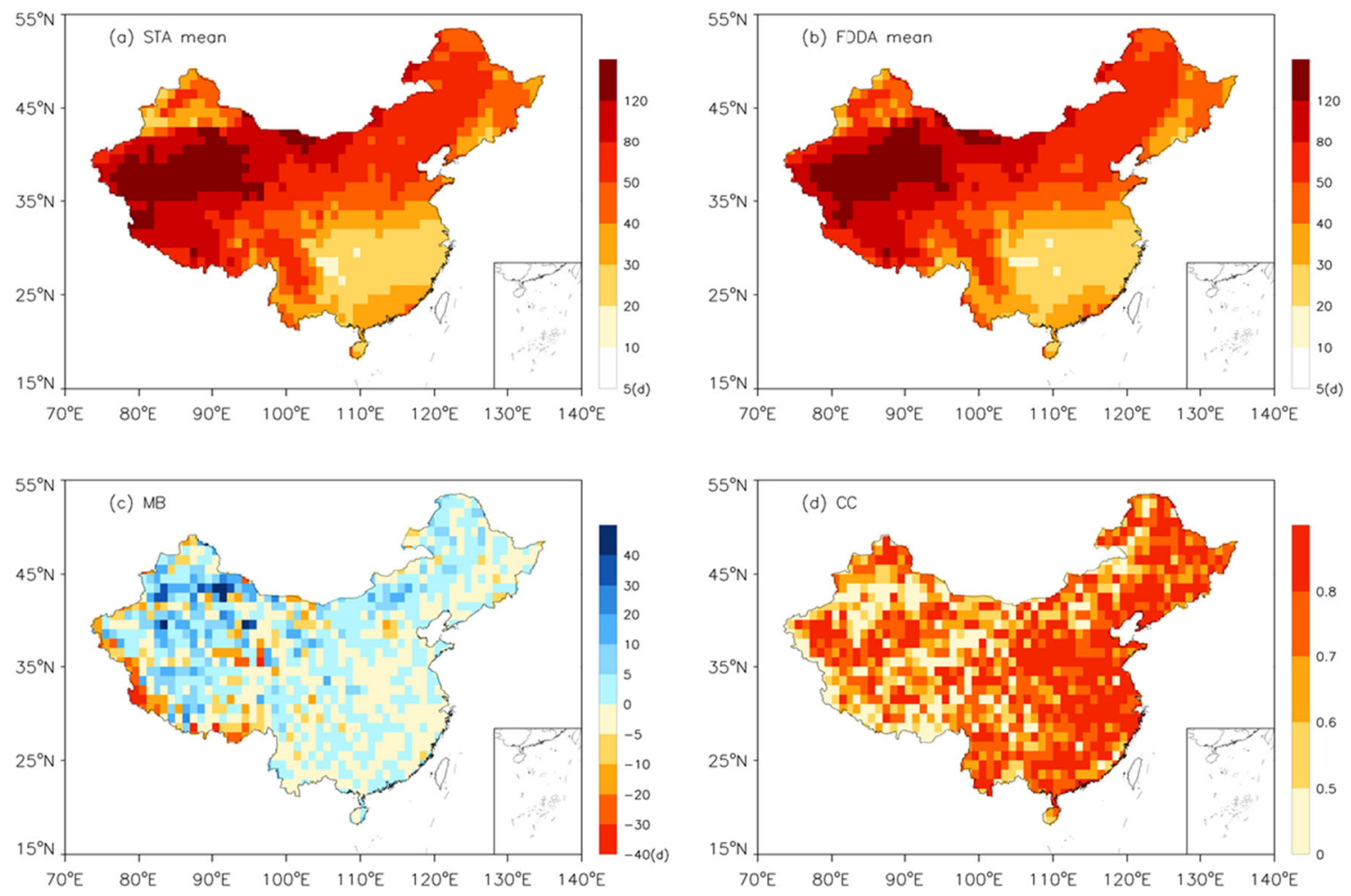

Fig. 5 Distribution of CDD index: (a) $\sim$ (d) the same as Fig. 3 but for CDD index
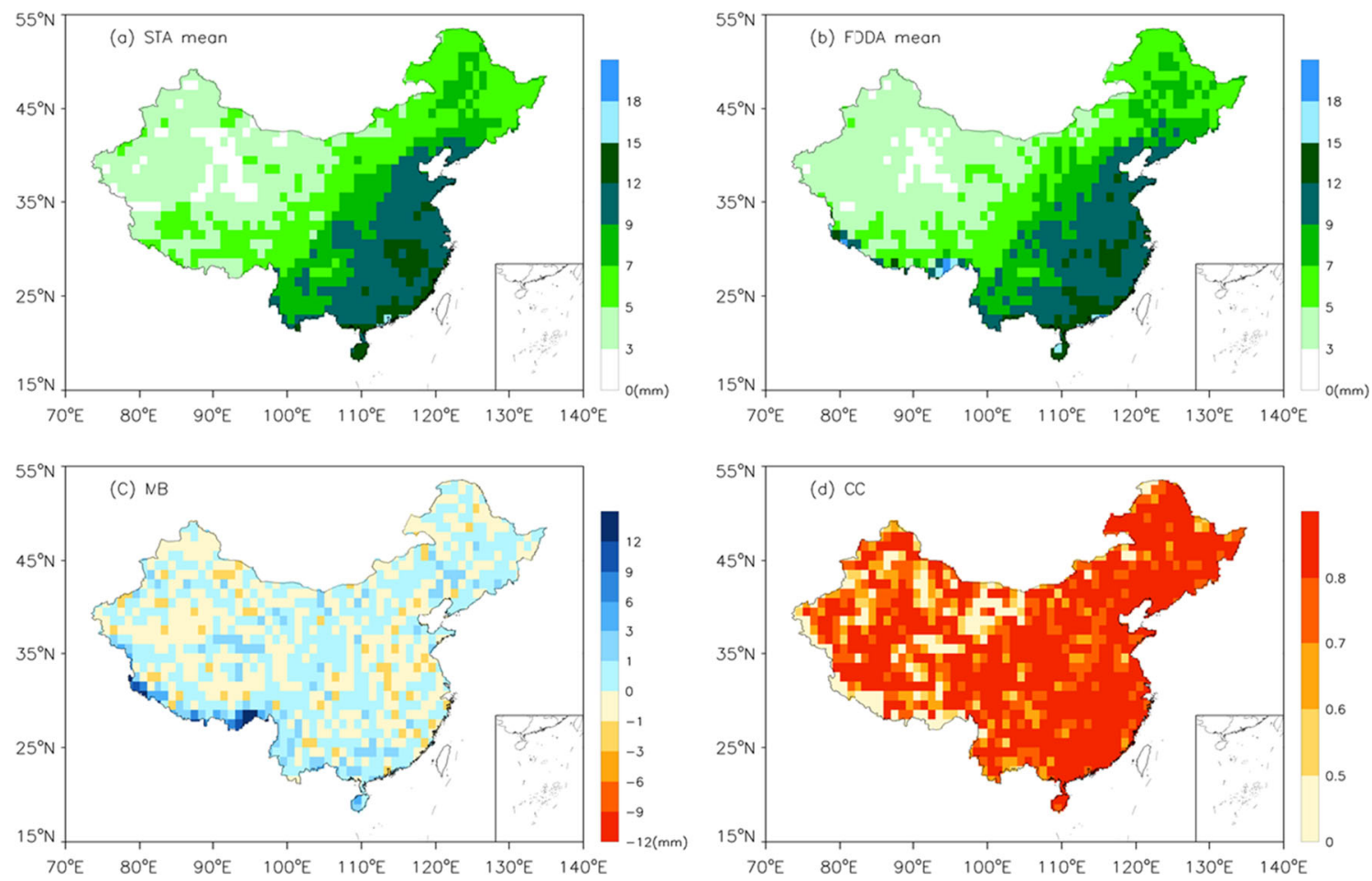

Fig. 6 Distribution of SDII index: (a) (d) the same as Fig. 3 but for SDII index 

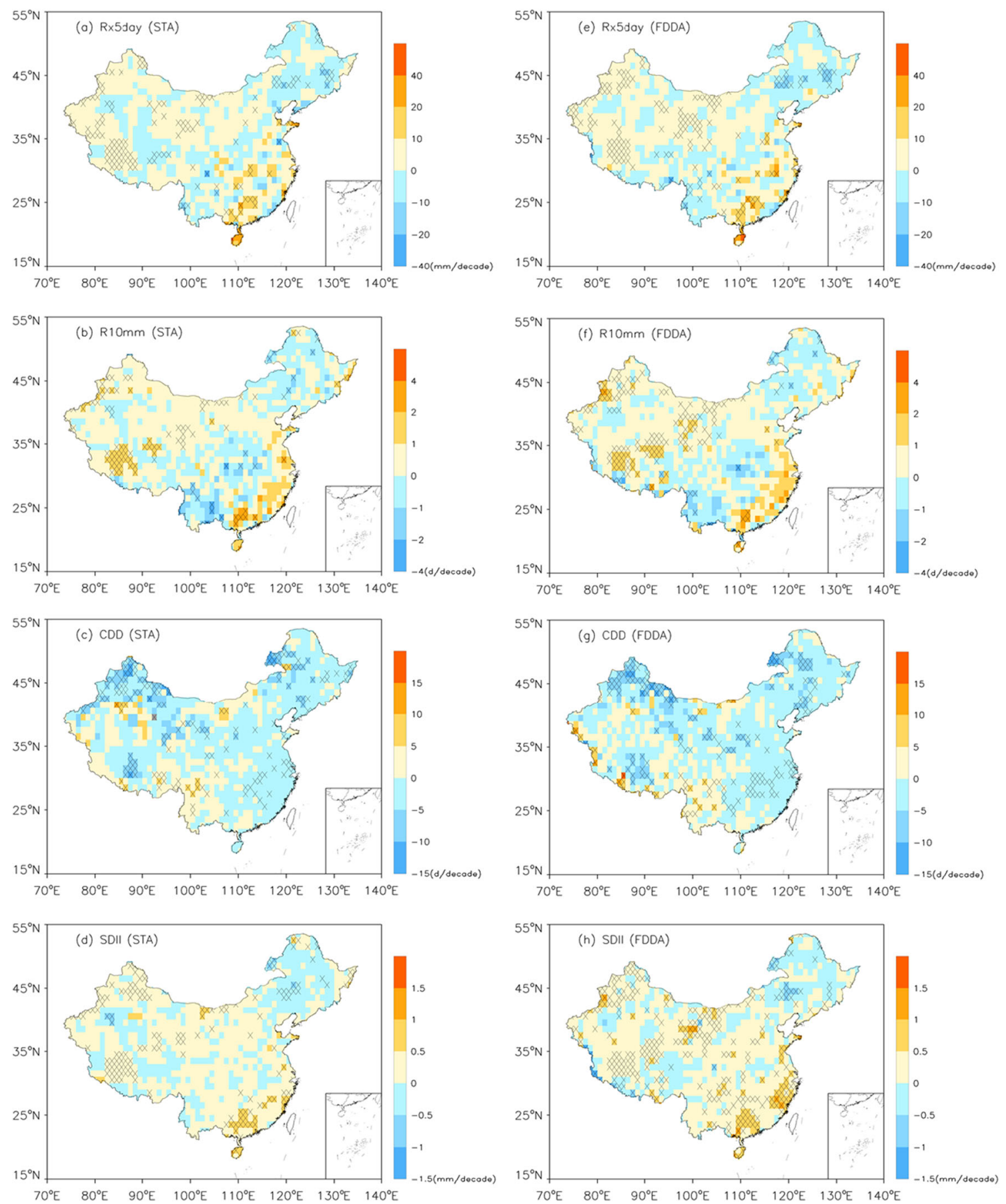

Fig. 7 Distribution of the trends of (a) Rx5day, (b)R10mm, (c) CDD and (d) SDII from STA; (e) (f) are distribution of the trends of the same indices from FDDA (significant trends for $p \leq 0.05$ are indicated with $\times$ )

\section{Discussion and conclusion}

Four indices Rx5day, R10mm, CDD and SDII calculated from daily precipitation of 2327 surface stations from 1982 to 2016 were utilized to evaluate the most recent release of the GPCC Full Data Daily Analysis (Version 2018) in its capability to capture precipitation extremes over the mainland of
China. Despite the fact that the GPCC FDDA dwells only on a limited data collective (less than a third of the large national data collection), the major patterns are very similar compared with the STA-based results.

For STA (see Fig.1a), the station density is much lower in West China than in Southeast China, being reflected by the average neighbour station searching range for the grids 
located in the area west of $105^{\circ} \mathrm{E}$ of about $107 \mathrm{~km}$, compared with about $61.5 \mathrm{~km}$ for the area east of $105^{\circ} \mathrm{E}$ is. Therefore, it is very reasonable that the distributions of $\mathrm{MB}$ are affected by the surface station density. As showing in MB distribution of Rx5day, R10mm, CDD and SDII, it is obvious that the other three indices except CDD were roughly around zero over almost entire China. But for CDD, the influence was stronger as a cluster of relatively large discrepancies existed in West China, which suggests that one should be cautious to analyse spatial distribution of CDD in this area. It is possible that Rx5day, R10mm and SDII may also be affected, but as the high values of these indices were all located in the Southeast of China, the affections were not apparent in MB. In spite of the bias in West China, it is interesting that the national mean of FDDAbased CDD was very coherent to STA-based one.

However, there are differences, and they become the more severe the lower the station density is in general, and the higher the natural variability of the observed precipitation is, which is a very plausible result. It is concluded that:

(1) All national means of Rx5day, R10mm, CDD and SDII calculated from STA and FDDA have similar variations and trends, respectively, and the correlation coefficient between each other is 0.94 or higher. Except for CDD, the national means of the other three FDDA-based indices across China are slightly higher than the STA-based ones. The mean biases between FDDA and STA in Rx5day, R10mm, CDD and SDII were $2.5 \mathrm{~mm}, 1.2$ days, 0.0 day and $0.3 \mathrm{~mm}$, respectively, for the period from 1982 to 2016. STA-based Rx5day, R10mm and SDII show increasing trends with $1.28 \mathrm{~mm} /$ decades, 0.14 days/decades and $0.09 \mathrm{~mm} /$ decades, respectively, while CDD has a negative trend of -1.01 days/decades.

(2) The distributions of the mean indices over China from both FDDA and STA have similar patterns. Relatively large discrepancies mostly occur at the southern edge of Tibetan Plateau, most likely caused by artefacts in the precipitation interpolation caused by the scarce data density there and lacking additional stations beyond the borders of China.

(3) As for the distribution of indices trends, CDD shows negative trends over almost entire China. Rx5day, R10mm and SDII also decline in Northeast China, while in Southeast China especially along the coastline, these three indices increase.

Although there are some differences between the FDDAand STA-based precipitation analyses, the FDDA shows a surprisingly high fidelity in reproducing almost the same patterns in the four ETCCDI indices chosen compared with the STA-based analysis. And the FDDA can be utilized to analyse the precipitation extremes across China.
Acknowledgements We appreciate the four anonymous reviewers for their valuable suggestions and questions.

Funding information This research is jointly supported by the National Natural Science Foundation of China (Grant 91744209 and 41805128).

Open Access This article is licensed under a Creative Commons Attribution 4.0 International License, which permits use, sharing, adaptation, distribution and reproduction in any medium or format, as long as you give appropriate credit to the original author(s) and the source, provide a link to the Creative Commons licence, and indicate if changes were made. The images or other third party material in this article are included in the article's Creative Commons licence, unless indicated otherwise in a credit line to the material. If material is not included in the article's Creative Commons licence and your intended use is not permitted by statutory regulation or exceeds the permitted use, you will need to obtain permission directly from the copyright holder. To view a copy of this licence, visit http://creativecommons.org/licenses/by/4.0/.

\section{References}

Alexander LV, Zhang X, Peterson TC, Caesar J, Gleason B, Klein Tank AMG, Haylock M, Collins D, Trewin B, Rahimzadeh F, Tagipour A, Rupa Kumar K, Revadekar J, Griffiths G, Vincent L, Stephenson DB, Burn J, Aguilar E, Brunet M, Taylor M, New M, Zhai P, Rusticucci M, Vazquez-Aguirre JL (2006) Global observed changes in daily climate extremes of temperature and precipitation. $\mathrm{J}$ Geophys Res 111:D05109. https://doi.org/10.1029/2005JD006290

Alexandersson H (1986) A homogeneity test applied to precipitation data. J Climatol 6:661-675. https://doi.org/10.1002/joc.3370060607

Becker A, Finger P, Meyer-Christoffer A, Rudolf B, Schamm K, Schneider U, Ziese M (2013) A description of the global landsurface precipitation data products of the Global Precipitation Climatology Centre with sample applications including centennial (trend) analysis from 1901-present. Earth Syst Sci Data 5:71-99. https://doi.org/10.5194/essd-5-71-2013

Buishand TA (1982) Some methods for testing the homogeneity of rainfall records. J Hydrol 58:11-27. https://doi.org/10.1016/00221694(82)90066-X

Frich P, Alexander LV, Della-Marta P, Gleason B, Haylock M, Klein Tank AMG, Peterson T (2002) Observed coherent changes in climate extremes during the second half of the twentieth century. Clim Res 19:193-212. https://doi.org/10.3354/cr019193

Gu G, Adler RF (2015) Spatial patterns of global precipitation change and variability during 1901-2010. J Clim 28:4431-4453. https://doi.org/ 10.1175/JCLI-D-14-00201.1

Herold N, Alexander LV, Donat MG, Contractor S, Becker A (2016) How much does it rain over land? Geophys Res Lett 43:341-348. https://doi.org/10.1002/2015GL066615

Jones PD, Hulme M (1996) Calculation regional climatic time series for temperature and precipitation: methods and illustrations. Int $\mathrm{J}$ Climatol 16:361-377

Kidd C, Bauer P, Turk J, Huffman GJ, Joyce R, Hsu K-L, Braithwaite D (2012) Intercomparison of high-resolution precipitation products over Northwest Europe. J Hydrometeorol 13:67-83. https://doi. org/10.1175/JHM-D-11-042.1

Kiktev D, Sexton DMH, Alexander LV, Folland CK (2003) Comparison of modeled and observed trends in indices of daily climate extremes. J Clim 16:3560-3571. https://doi.org/10.1175/1520-0442(2003) 016<3560:COMAOT>2.0.CO;2

Menne MJ, Durre I, Vose RS, Gleason BE, Houston TG (2012) An overview of the global historical climatology network-daily 
database. J Atmos Ocean Tech 29:897-910. https://doi.org/10.1175/ JTECH-D-11-00103.1

Negrón Juárez RI, Li W, Fu R, Fernandes K, Cardoso AO (2009) Comparison of precipitation datasets over the tropical South American and African continents. J Hydrometeorol 10:289-299. https://doi.org/10.1175/2008JHM1023.1

New M, Hulme M, Jones P (2000) Representing twentieth-century spacetime climate variability. Part II: development of 1901-96 monthly grids of terrestrial surface climate. J Clim 13:2217-2238

Peng Y, Zhao X, Wu D, Tang B, Xu P, Du X, Wang H (2018) Spatiotemporal variability in extreme precipitation in China from observation and projections. Water 10:1089. https://doi.org/10. 3390/w10081089

Pettitt AN (1979) A non-parametric approach to the change-point detection. Appl Statist 28:126-135

Prakash S, Gairola RM, Mitra AK (2015) Comparison of large-scale global land precipitation from multisatellite and reanalysis products with gauge-based GPCC data sets. Theor Appl Climatol 121:303317. https://doi.org/10.1007/s00704-014-1245-5

Schneider U, Becker A, Finger P, Meyer-Christoffer A, Ziese M, Rudolf B (2014) GPCC's new land surface precipitation climatology based on quality-controlled in situ data and its role in quantifying the global water cycle. Theor Appl Climatol 115:15-40. https://doi. org/10.1007/s00704-013-0860-x

Schneider U, Finger P, Meyer-Christoffer A, Rustemeier E, Ziese M, Becker A (2017) Evaluating the hydrological cycle over land using the newly-corrected precipitation climatology from the Global Precipitation Climatology Centre (GPCC). Atmosphere 8(3):52. https://doi.org/10.3390/atmos8030052

Shepard D (1968) A two-dimensional interpolation function for irregularly spaced data. Proc. 23rd ACM Nat. Conf., Brandon/systems press, Princeton, pp 517-524
Trenberth KE (2011) Changes in precipitation with climate change. Clim Res 47:123-138. https://doi.org/10.3354/cr00953

von Neumann J (1941) Distribution of the ratio of the mean square successive difference to the variance. Ann Math Statist 12:367-395. https://doi.org/10.1214/aoms/1177731677

Wijngaard JB, Klein Tank AMG, Konnen GP (2003) Homogeneity of 20th century European daily temperature and precipitation series. Int J Climatol 23:679-692. https://doi.org/10.1002/joc.906

Zhai P, Sun A, Ren F, Liu X, Gao B, Zhang Q (1999) Changes of climate extremes in China. Clim Chang 42:203-218. https://doi.org/10. 1023/A:1005428602279

Zhai P, Zhang X, Wan H, Pan X (2005) Trends in total precipitation and frequency of daily precipitation extremes over China. J Clim 18: 1096-1108

Zhang L, Zhou T (2011) An assessment of monsoon precipitation changes during 1901-2001. Clim Dyn 37:279-296. https://doi.org/10. 1007/s00382-011-0993-5

Zhang X, Alexander LV, Hegerl GC, Jones P, Tank AK, Peterson TC, Trewin B, Zwiers FW (2011) Indices for monitoring changes in extremes based on daily temperature and precipitation data. WIREs Clim Change 2:851-870. https://doi.org/10.1002/wcc.147

Zittis G (2018) Observed rainfall trends and precipitation uncertainty in the vicinity of the Mediterranean, Middle East and North Africa. Theor Appl Climatol 134:1207-1230. https://doi.org/10.1007/ s00704-017-2333-0

Publisher's note Springer Nature remains neutral with regard to jurisdictional claims in published maps and institutional affiliations. 